\title{
A Two-Period Open-Label, Single-Dose Crossover Study in Healthy Volunteers to Evaluate the Drug-Drug Interaction Between Cimetidine and Inhaled Extrafine CHF 5993
}

\author{
Fabrizia Mariotti $^{1} \cdot$ Giorgia Ciurlia $^{1} \cdot$ Luca Spaccapelo $^{1} \cdot$ Annamaria Muraro $^{1} \cdot$ \\ Daniela Acerbi ${ }^{1}$
}

Published online: 21 May 2016

(C) The Author(s) 2016. This article is published with open access at Springerlink.com

\begin{abstract}
Background and Objectives CHF 5993 is an extrafine 'triple therapy' combination of the long-acting muscarinic antagonist glycopyrronium bromide (GB), the long-acting $\beta_{2}$-agonist formoterol fumarate (FF), and the inhaled corticosteroid beclometasone dipropionate (BDP). It is in development for chronic obstructive pulmonary disease and asthma delivered via pressurised metered-dose inhaler. Methods This two-period, open-label, crossover study examined the drug-drug interaction of CHF 5993 and cimetidine. In one period, subjects received cimetidine $800 \mathrm{mg}$ twice daily for 6 days; on the fourth day they also received CHF 5993 (BDP/FF/GB 400/24/100 $\mu$ g). In the other, they received CHF 5993 alone. Primary objective was to compare the area under the plasma concentrationtime curve from time 0 to last quantifiable concentration $\left(\mathrm{AUC}_{0-\mathrm{t}}\right)$ of $\mathrm{GB}$, with and without cimetidine. Secondary endpoints included $\mathrm{GB} \mathrm{AUC}_{0-12 \mathrm{~h}}$, maximum concentration $\left(C_{\max }\right)$, time to $C_{\max }\left(t_{\max }\right)$, elimination half-life $\left(t_{1 / 2}\right)$ and urinary excretion. Pharmacokinetic parameters of BDP, beclometasone-17-monopropionate (B17MP; active metabolite of BDP) and formoterol were also evaluated.

Results Twenty-six subjects were randomised; 25 completed. Co-administration of CHF 5993 and cimetidine
\end{abstract}

ClinicalTrials.gov: NCT02287272.

Electronic supplementary material The online version of this article (doi:10.1007/s13318-016-0345-2) contains supplementary material, which is available to authorized users.

Fabrizia Mariotti

F.Mariotti@chiesi.com

1 Global Clinical Development, Chiesi Farmaceutici SpA, Largo Belloli 11/A, 43122 Parma, Italy resulted in small, statistically significant increases in GB $\mathrm{AUC}_{0-\mathrm{t}}, \mathrm{AUC}_{0-12 \mathrm{~h}}$ and $C_{\max }$ vs CHF 5993 (ratios 1.16, 1.21 and 1.26 , respectively); $t_{1 / 2}, t_{\max }$ and urinary excretion were unaffected. There were small, statistically significant increases in formoterol $\mathrm{AUC}_{0-\mathrm{t}}, \mathrm{AUC}_{0-24 \mathrm{~h}}$ and $t_{1 / 2}$ following co-administration of cimetidine and CHF 5993; urinary excretion was unaffected. There were no significant differences for either BDP or B17MP. There were few adverse events (AEs), and no serious AEs.

Conclusions Overall, this study indicates that there is no clinically relevant drug-drug interaction between $\mathrm{CHF}$ 5993 and cimetidine.

\section{Key Points}

This study evaluated the drug-drug interaction between CHF 5993 (a triple combination inhaler containing glycopyrronium bromide [GB], formoterol fumarate, and beclometasone dipropionate) and cimetidine.

The component of CHF 5993 of particular interest in terms of this potential interaction is GB. There were small, although statistically significant, increases in a number of the GB plasma pharmacokinetic parameters as a result of cimetidine co-administration, with total exposure increased by $16 \%$, and peak concentration by $26 \%$.

The safety of GB has been evaluated at a dose up to 8 times the minimally effective dose in patients with COPD, and so this study indicates that there is no clinically relevant drug-drug interaction between CHF 5993 and cimetidine. 


\section{Introduction}

One of the prescribed maintenance treatments indicated for chronic obstructive pulmonary disease (COPD) is an inhaled combination of a long-acting $\beta_{2}$-agonist (LABA), long-acting muscarinic antagonist (LAMA) and inhaled corticosteroid (ICS) [1]. Such 'triple therapy' has been shown to provide clinical benefits to patients in terms of bronchodilation, dyspnoea, exacerbations and mortality [26], yet currently to administer such a combination requires at least two inhalers, often of different types, adding complexity to patients' treatment. CHF 5993 is a combination of the LAMA glycopyrronium bromide (GB), the LABA formoterol fumarate (FF) and the ICS beclometasone dipropionate (BDP), in development for the management of COPD and asthma, delivered via a pressurised metered-dose inhaler (pMDI). The same pMDI format is also used for a fixed combination of FF and BDP (Foster ${ }^{\circledR}$, Chiesi Farmaceutici SpA, Parma, Italy) approved for asthma and COPD. All three components of CHF 5993 are formulated as extrafine particles, which support higher total lung delivery as well as deeper and more uniform distribution within the airways [7]. An early study conducted in healthy volunteers compared the pharmacokinetics of FF/ BDP plus GB (in separate pMDIs) with CHF 5993 [8]. There were no clinically relevant differences between the free and fixed combinations in any pharmacokinetic parameter assessed, suggesting that there is no biopharmaceutical interaction as a result of co-formulating the three molecules in a single inhaler.

The potential for drug-drug interactions with CHF 5993 was investigated focusing predominantly on $\mathrm{GB}$, which, based on pharmacokinetic characteristics, is expected to be the CHF 5993 component more susceptible to interaction with other drugs. BDP undergoes rapid metabolism via esterase enzymes to the active metabolite beclometasone17-monopropionate (B17MP) [9, 10], with both BDP and B17MP mainly eliminated in the faeces [9]. FF is primarily metabolised in the liver by direct glucuronidation and $O$ demethylation followed by conjugation to inactive metabolites, then urinary excretion [11-13]. $O$-Demethylation is primarily due to cytochrome P450 (CYP) - in particular CYP2D6 and CYP2C9 [14]. In contrast, GB is eliminated by both hepatic and renal routes. In a series of in vitro studies, GB was shown to be a substrate of organic cation transporter 1 (OCT1) (Michaelis constant $\left.\left[K_{\mathrm{m}}\right]=43.6 \mu \mathrm{M}\right)$, of organic cation transporter $2(\mathrm{OCT} 2)$ $\left(K_{\mathrm{m}}=14.1 \mu \mathrm{M}\right)$ and of multidrug and toxin extrusion transporter 1 (MATE1) $\left(K_{\mathrm{m}}=62.1 \mu \mathrm{M}\right)$ (data on file; Chiesi Farmaceutici SpA). OCT1 is expressed predominantly in the liver, OCT2 in the kidney, and MATE1 in both organs. OCT1 and OCT2 are uptake transporters, responsible for removing substrates from the blood, whereas MATE1 is responsible for elimination of its substrates into the urine or bile. Ideally, to study GB drugdrug interactions, inhibitors of OCT1, OCT2 and MATE1 are needed. The inhibitors of OCT1 currently available (e.g. quinine, quinidine and disopyramide [15]) are unsuitable for use in clinical trials, as the doses required to induce significant inhibition are toxic. Cimetidine, however, has been shown to inhibit both OCT2 and MATE1 when administered at an oral dose of $800 \mathrm{mg}$ twice daily (BID) [16, 17], which is below the maximum dose that has been approved for the treatment of duodenal and gastric ulcer (2.4 g daily) [18] and it is, therefore, an ideal candidate for studying OCT2 and MATE1-related interactions. Cimetidine is also a typical inhibitor of cytochrome P450 (including CYP2D6 and CYP2C9) [14], and could also be anticipated to exhibit a drug-drug interaction with FF. The aim of this study was to examine the pharmacokinetic and safety profile of CHF 5993 with and without cimetidine. The evaluation was conducted in healthy volunteers, and at steady state of cimetidine. The primary objective was to evaluate the pharmacokinetic interaction when CHF 5993 was administered with cimetidine, by comparing the area under the plasma concentration-time curve from time 0 to the last quantifiable concentration $\left(\mathrm{AUC}_{0-\mathrm{t}}\right)$ of $\mathrm{GB}$, after a single dose of CHF 5993 administered alone or at steady state of cimetidine. Secondary objectives included comparison of the other pharmacokinetic parameters of GB and of the systemic exposure of BDP, B17MP and formoterol, in terms of $\mathrm{AUC}_{0-\mathrm{t}}, \mathrm{AUC}_{0-12 \mathrm{~h}}, \mathrm{AUC}_{0-24 \mathrm{~h}}$, maximum concentration $\left(C_{\max }\right)$, time to maximum concentration $\left(t_{\max }\right)$, and plasma elimination half-life $\left(t_{1 / 2}\right)$. In addition, the urinary excretion of GB and formoterol was evaluated with respect to the amount of drug excreted into the urine in the collection interval (Ae), the fraction excreted (fe) and urinary clearance (CLr).

\section{Subjects and Methods}

\subsection{Trial Design}

This two-period, two-way crossover design, open-label study started with a screening visit to assess subject eligibility 3-21 days before randomisation. In one treatment period, subjects received cimetidine + CHF 5993 (Table 1); in the other, they received CHF 5993 alone, with a 10- to 14-day wash-out period between CHF 5993 administrations in the two treatment periods.

The cimetidine + CHF 5993 treatment period lasted seven days. On Days -3 and -2 , subjects received the morning dose of cimetidine at the clinic, and were 
Table 1 Visit structure and administration scheme

\begin{tabular}{llllll}
\hline Treatment period & Time & \multicolumn{2}{l}{ Days in treatment period } & & Days 2 and 3 \\
\cline { 3 - 6 } & & Days -3 and -2 & Day -1 & Day 1 & Cimetidine \\
\hline Cimetidine + CHF 5993 & Morning & Cimetidine & Cimetidine & Cimetidine + CHF 5993 & Cimetidine \\
& Evening & Cimetidine & Cimetidine & Cimetidine & \\
CHF 5993 & Morning & & CHF 5993 & \\
& Evening & & & & \\
\hline
\end{tabular}

a Taken at home

instructed to take the evening dose at home. From the morning of Day -1 to the evening of Day 3, subjects received all doses of cimetidine at the clinic, with the dose of CHF 5993 taken on the morning of Day 1. In the CHF 5993 treatment period, the dose of CHF 5993 was taken on the morning of Day 1. In both treatment periods, subjects remained in the clinic from the evening of Day -1 (the evening prior to CHF 5993 dosing) and up to Day 4, with the final assessments on the morning of Day 4.

Blood samples for CHF 5993 evaluation were collected pre-dose and at 5, 10, 15 and $30 \mathrm{~min}$, and 1, 2, 4, 6, 8, 12, $24,36,48$ and $72 \mathrm{~h}$ post-dose in each treatment period. Samples for cimetidine evaluation were collected before the morning administration of cimetidine from Day -2 to Day 3, with a final sample collected on the morning of Day 4. Plasma was separated in a refrigerated centrifuge $\left(+4{ }^{\circ} \mathrm{C}\right)$ at $2500 \mathrm{~g}$ for $15 \mathrm{~min}$. Urine was collected for evaluation of GB and formoterol at pre-dose, and 0-4, 4-8, $8-12,12-24,24-36,36-48,48-60$ and $60-72 \mathrm{~h}$ post-dose. Plasma and urine samples were analysed in a central laboratory using validated liquid chromatography $[19,20]$ followed by tandem mass spectrometry detection methods. GB concentration levels were determined in lithium-heparinised plasma and in bovine serum albumin urine after solid/liquid extraction. The GB lower limits of quantification (LLOQs) were 5.00 and $20.0 \mathrm{pg} / \mathrm{mL}$ in plasma and urine, respectively. Formoterol concentration levels were determined in acidified lithium-heparinised plasma and in urine, as free and total fractions, following a solid/liquid extraction of the samples. The formoterol LLOQs were 2.00 and $10.0 \mathrm{pg} / \mathrm{mL}$ in plasma and urine, respectively. Concentration levels of BDP and its metabolite B17MP were determined in dipotassium ethylene diamine tetraacetic acid $\left(\mathrm{K}_{2}\right.$ EDTA) human plasma after liquid/liquid extraction. The BDP and B17MP LLOQ in plasma was $20.0 \mathrm{pg} / \mathrm{mL}$. Cimetidine was analysed in lithium-heparinised plasma samples after protein precipitation extraction, with an LLOQ of $5.0 \mathrm{ng} / \mathrm{mL}$. The detailed analytical methods are described in the supplementary material.

Other than study medication, no drug treatment was permitted from 14 days prior to the screening visit until completion of the last study procedures, with the exception of occasional paracetamol and of hormonal contraceptives and hormone replacement treatment for post-menopausal women. Alcohol and xanthine-containing foods or beverages or grapefruit-containing foods or beverages were not permitted from $48 \mathrm{~h}$ prior to each intake of CHF 5993 until the end of the treatment period. Caffeine was limited to 5 cups or glasses per day of caffeinated beverages. Subjects were fasted for at least $10 \mathrm{~h}$ prior to CHF 5993 dosing until $2 \mathrm{~h}$ post-dose; fluid intake was forbidden from $1 \mathrm{~h}$ prior to dosing until $1 \mathrm{~h}$ post-dose.

The study is registered at ClinicalTrials.gov (NCT02287272).

\subsection{Participants}

The study recruited healthy males and females, aged $18-45$ years, and with body mass index between 18 and $30 \mathrm{~kg} / \mathrm{m}^{2}$, inclusive. All subjects were to have serum creatinine within the normal range $(0.7-1.2 \mathrm{mg} / \mathrm{dL})$ and an estimated glomerular filtration rate $>80 \mathrm{~mL} / \mathrm{min} / 1.73 \mathrm{~m}^{2}$. Non- or ex-smokers (with a smoking history $<5$ packyears) were eligible. The main exclusion criteria were clinically relevant laboratory values or conditions, including abnormal electrocardiogram (ECG) or systolic or diastolic blood pressure, and contraindication to the use of anticholinergics, or hypersensitivity to the treatments or excipients used during the study.

\subsection{Interventions}

All study medications were open label. In both treatment periods, subjects received a single dose of four consecutive inhalations of CHF 5993 (BDP/FF/GB 100/6/25 $\mu \mathrm{g}$ per actuation) via pMDI, giving a total dose of $400 \mu \mathrm{g}$ of BDP, $24 \mu \mathrm{g}$ of FF and $100 \mu \mathrm{g}$ of GB. The GB dose $(100 \mu \mathrm{g})$ was anticipated to provide measurable pharmacokinetic data over a full 24-h period. In one of the two treatment periods, subjects received cimetidine $800 \mathrm{mg}$ (2 tablets of cimetidine $400 \mathrm{mg}$ ) BID for 6 days. Subjects were randomised to one of two treatment sequences according to a 
randomisation list that was generated by the Statistics and Data Management Department of Chiesi Farmaceutici SpA (the study sponsor) using a validated computerised system.

\subsection{Statistical Methods}

The pharmacokinetic analysis was performed using Phoenix 6.2 or later (Pharsight Corporation, Palo Alto, CA, USA). Standard non-compartmental methods were used for the calculation of the plasma parameters from the individual plasma drug concentrations versus time profile (see supplementary material).

The primary endpoint, plasma $\mathrm{GB} \mathrm{AUC}_{0-\mathrm{t}}$, was log transformed and analysed using a linear model including treatment, sequence, period and subject within sequence as fixed effects. The ratios of adjusted geometric means between CHF 5993 + cimetidine and CHF 5993 alone were calculated with their $90 \%$ two-sided confidence intervals (CIs). Most of the secondary plasma pharmacokinetic objectives were also log transformed and analysed using this linear model. The exception was $t_{\max }$, for which the Hodges-Lehmann non-parametric estimate of location shift between treatments (based on untransformed data) is provided with its $90 \%$ two-sided CI. Urinary excretion was summarised by treatment using descriptive statistics.

It was planned for all pharmacokinetic values below the lower limit of quantification (LLOQ; $5 \mathrm{pg} / \mathrm{mL}$ ) to be set to 0 . However, since GB concentrations were below the LLOQ starting from $4 \mathrm{~h}$ post-dose and samples were collected over $72 \mathrm{~h}$ post-dose, a large portion of the GB plasma concentration vs time curve could not be accurately assessed in a number of subjects. A post hoc analysis was therefore conducted, setting post-dose values below the LLOQ to LLOQ/2, to provide an 'average' estimate of the actual concentration fluctuating between the LLOQ and zero and, consequently, to better estimate GB pharmacokinetic parameters. This approach was used for all GB parameters reported here, except $t_{1 / 2}$ (the flat elimination phase due to all data being set to LLOQ/2 did not allow the estimation of $t_{1 / 2}$ using this method, so the original methodology was used).

Compliance with cimetidine was calculated on the basis of the used/unused drug returned by each subject, as the percentage of scheduled doses actually taken. As CHF 5993 was only administered in study centres, compliance was evaluated on the basis of the number of correct inhalations recorded in the electronic Case Report Form.

Pharmacokinetic variables were analysed on the pharmacokinetic population, which was all subjects from the safety population excluding subjects without any valid pharmacokinetic measurement or with major protocol deviations significantly affecting pharmacokinetics.

\subsection{Safety and Tolerability}

The safety and tolerability of study treatment was evaluated by recording adverse events (AEs) and serious adverse events (SAEs) were recorded. The number of subjects who experienced at least one treatment-emergent AE (TEAE), treatment-related AE, serious TEAE, seriousness-related TEAE, or TEAE leading to study drug discontinuation or death were summarised by treatment.

Adverse events were captured from the time that a subject signed informed consent until their participation in the study ended. An AE was defined as 'any untoward medical occurrence in a patient or clinical trial subject administered a medicinal product and which does not necessarily have a causal relationship with this treatment'. An SAE was defined as an event that resulted in death, or persistent or significant disability or incapacity, was lifethreatening, required (or prolonged) hospitalisation, was a congenital abnormality or birth defect, or was medically significant. AEs were rated by the reporting investigator on a three-point scale:

- Mild: the event causes a minor discomfort, or does not interfere with daily activity of the subject, or does not lead to either modification of test treatment dosage or establishment of a correcting treatment.

- Moderate: the event perturbs the usual activity of the subject and is of a sufficient severity to make the subject uncomfortable. The event leads to a diminution of dosage of the test treatment, or a temporary interruption of its administration or to the establishment of a correcting treatment.

- Severe: the event prevents any usual routine activity of the subject and causes severe discomfort. It may be of such severity to cause the definitive interruption of test treatment.

All safety variables were analysed on the safety population, which comprised all randomised subjects who received at least one dose of study treatment.

\subsection{Sample Size}

The sample size calculation was not based on the power to investigate a formal hypothesis, but was conducted to evaluate the precision of the estimate of the adjusted means ratio for $\mathrm{GB} \mathrm{AUC}_{0-\mathrm{t}}$. Estimating a within-subject coefficient of variation of $32.9 \%$, a total sample size of 22 evaluable subjects ( 11 per sequence) would ensure that the lower and upper limit of the $90 \% \mathrm{CI}$ for the ratio of the adjusted means corresponded approximately to the 85 and $118 \%$ of the point estimate of the ratio. Considering a screening failure rate of approximately $50 \%$ and a nonevaluable rate of approximately $10 \%$, a total of about 52 
subjects were to be screened and 26 (13 per sequence) were to be randomised.

\section{Results}

\subsection{Participants}

In total, 43 subjects were screened (Fig. 1). Seventeen subjects were not randomised (11 subjects were not eligible to enter the study, 3 withdrew consent and 3 were backups). The other 26 subjects were randomised ( $54 \%$ female, mean age 33.1 years, $84.6 \%$ non-smokers; Table 2), one subsequently withdrawing consent before receiving CHF 5993 but after having received cimetidine for 3 days. The remaining 25 subjects completed the study, and compliance with both cimetidine and CHF 5993 was $100 \%$.

\subsection{Outcomes}

\subsubsection{GB Pharmacokinetics}

The co-administration of CHF 5993 and cimetidine resulted in small but statistically significant increases in $\mathrm{AUC}_{0-\mathrm{t}}, \mathrm{AUC}_{0-12 \mathrm{~h}}$ and $C_{\max }$ compared with CHF 5993 alone, since the lower limit of the $90 \%$ CI of the ratio exceeded 1.0, whereas $t_{1 / 2}$ was unchanged (Table 3). Mean plasma GB levels reached a peak by the first post-dose sampling time point $(5 \mathrm{~min})$, and then declined rapidly (Fig. 2). At $4 \mathrm{~h}$ post-dose, GB plasma concentration values were below the LLOQ for one subject following administration of cimetidine + CHF 5993 and three subjects following administration of CHF 5993. By $8 \mathrm{~h}$ post-dose mean GB levels for both treatments were below the LLOQ in most subjects. Overall urinary excretion of GB was

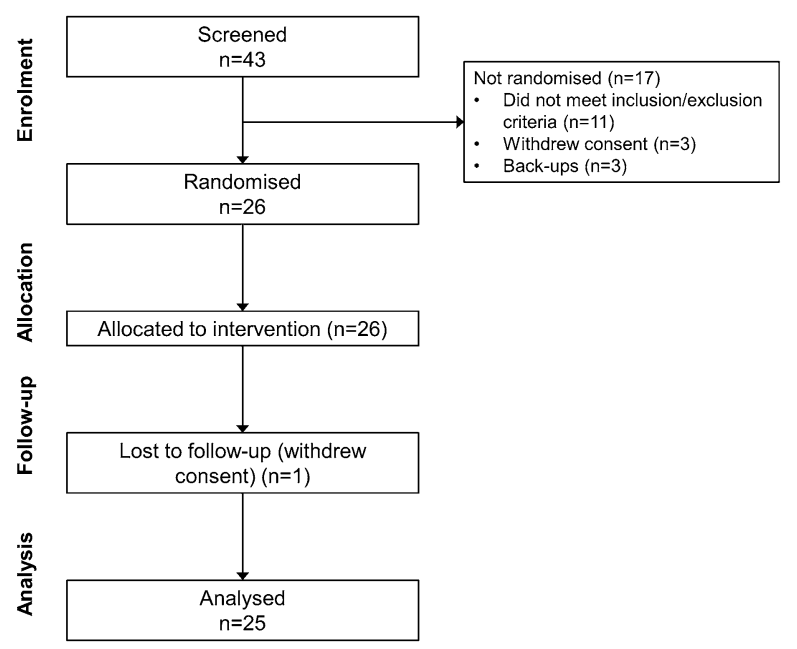

Fig. 1 Subject flow through the study
Table 2 Baseline characteristics (all randomised population)

\begin{tabular}{ll}
\hline Characteristic & $\begin{array}{l}\text { Value } \\
(N=26)\end{array}$ \\
\hline Sex, $n(\%)$ & $14(54)$ \\
Female & $12(46)$ \\
Male & \\
Race, $n(\%)$ & $25(96)$ \\
White & $1(4)$ \\
Black & \\
Age (years) & $33.1(8.2)$ \\
Mean (SD) & $21-45$ \\
Range & \\
Body mass index, kg/m ${ }^{2}$ & $24.1(3.4)$ \\
Mean (SD) & $17.4-29.4$ \\
Range & \\
Smoking status, $n(\%)$ & $22(84.6)$ \\
Non-smoker & $4(15.4)$ \\
Ex-smoker & 0 \\
Current smoker & $95.3(12.7)$ \\
Glomerular filtration rate, mean (SD), mL/min/ & \\
$1.73 \mathrm{~m}^{2}$ & \\
\hline
\end{tabular}

unaffected by the co-administration of cimetidine (Fig. 3). Approximately, half of the total excretion occurred in the first $12 \mathrm{~h}$ (44 and $47 \%$ for cimetidine + CHF 5993 and CHF 5993, respectively). CLr of total GB was significantly lower for cimetidine + CHF 5993 compared with CHF 5993 (Table 3). In a post hoc analysis, unbound GB CLr was 491 and $547 \mathrm{~mL} / \mathrm{min}$ for cimetidine + CHF 5993 and CHF 5993 alone, respectively.

\subsubsection{Formoterol, B17MP and BDP Pharmacokinetics}

There were small but statistically significant increases in formoterol $\mathrm{AUC}_{0-\mathrm{t}}, \mathrm{AUC}_{0-24 \mathrm{~h}}$ and $t_{1 / 2}$ following co-administration of cimetidine + CHF 5993 compared with CHF 5993 alone, but no significant change in $C_{\max }$ (Table 4). Urinary excretion of formoterol was unaffected by co-administration of cimetidine, with more than half of the total excretion occurring in the first $4 \mathrm{~h}$ post-dose (Fig. 4). Formoterol CLr was significantly lower following co-administration of cimetidine + CHF 5993 than following CHF 5993 alone (mean \pm SD $231 \pm 78.5$ and $313 \pm 98.2 \mathrm{~mL} / \mathrm{min}$ respectively; ratio $0.75,90 \% \mathrm{CI} 0.65,0.85$ ). There were no statistically significant differences in any of the plasma pharmacokinetic parameters for either BDP or B17MP.

\subsubsection{Cimetidine Pharmacokinetics}

Mean pre-dose cimetidine plasma concentrations were $312.7,361.8,270.2,331.7,308.9$ and $312.7 \mathrm{ng} / \mathrm{mL}$ from 
Table 3 GB pharmacokinetic parameters (pharmacokinetic population)

\begin{tabular}{llll}
\hline Parameter & Cimetidine + CHF 5993 $(N=25)$ & CHF 5993 $(N=25)$ & Ratio $^{\mathrm{g}}(90 \% \mathrm{CI})$ \\
\hline Plasma & & & \\
$\mathrm{AUC}_{0-\mathrm{t}}(\mathrm{pg} \cdot \mathrm{h} / \mathrm{mL})$ & $330 \pm 138^{\mathrm{a}}$ & $272 \pm 70.6$ & $1.16(1.07,1.27)$ \\
$\mathrm{AUC}_{0-12 \mathrm{~h}}(\mathrm{pg} \cdot \mathrm{h} / \mathrm{mL})$ & $138 \pm 69.6^{\mathrm{a}}$ & $111 \pm 51.0$ & $1.21(1.08,1.36)$ \\
$C_{\max }(\mathrm{pg} / \mathrm{mL})$ & $63.3 \pm 57.0$ & $47.8 \pm 40.6$ & $1.26(1.00,1.58)$ \\
$t_{\max }(\mathrm{h})$ & $0.08(0.08 ; 4.02)$ & $0.08(0.05 ; 2.00)$ & $0.00(0.00,0.42)$ \\
$t_{1 / 2}(\mathrm{~h})$ & $2.86 \pm 0.71^{\mathrm{b}}$ & $3.73 \pm 1.78^{\mathrm{c}}$ & $1.02(0.78,1.35)$ \\
Urine & & & \\
fe $(\%)$ & $5.83 \pm 3.34^{\mathrm{d}}$ & $5.36 \pm 2.34^{\mathrm{e}}$ & Not evaluated \\
CLr $(\mathrm{mL} / \mathrm{min})$ & $296 \pm 196^{\mathrm{f}}$ & $330 \pm 127^{\mathrm{e}}$ & $0.80(0.71,0.90)$ \\
\hline
\end{tabular}

Data are mean \pm standard deviation, except $t_{\max }$ which is median (range)

$C I$ confidence interval, $A U C_{0-t}$ area under the plasma concentration-time curve from time 0 to the last quantifiable concentration, $A U C_{0-12 h}$ area under the plasma concentration-time curve from time 0 to $12 \mathrm{~h}$ post-dose, $C_{\max }$ maximum concentration, $t_{\max }$ time to maximum concentration, $t_{1 / 2}$ plasma elimination halflife, $f e$ fraction excreted, $C L r$ urinary clearance, $G B$ glycopyrronium bromide

${ }^{\text {a }} N=24$

${ }^{\mathrm{b}} N=8$

${ }^{\mathrm{c}} N=13$

${ }^{\mathrm{d}} N=23$

e $N=21$

${ }^{\mathrm{f}} N=22$

g Ratio of adjusted geometric means, except $t_{\max }$ (see Sect. 2.4)

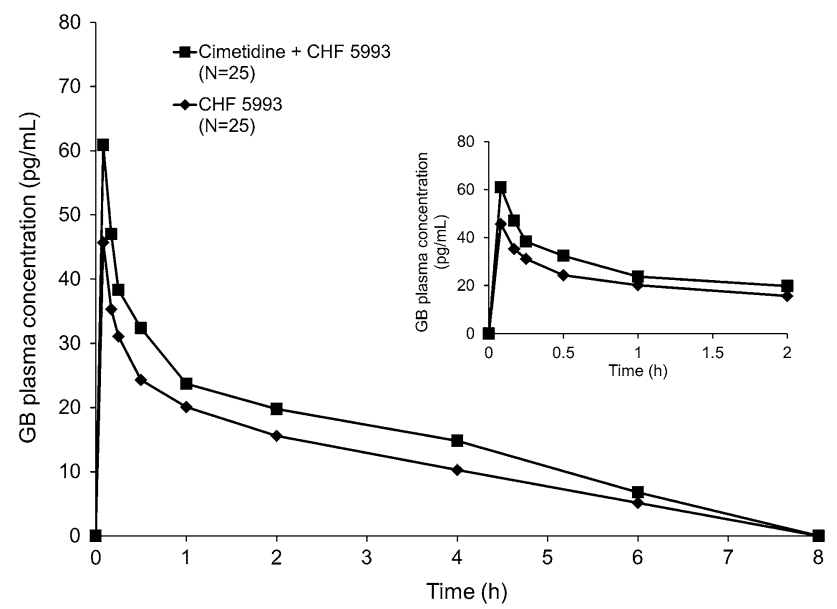

Fig. 2 Mean GB plasma concentration vs time profiles, up to $8 \mathrm{~h}$ post-dose (main figure) and up to $2 \mathrm{~h}$ post-dose (inset figure) (pharmacokinetic population). $G B$ glycopyrronium bromide

the morning of Day -2 to Day 4, indicating that cimetidine was at steady state throughout the assessment of CHF 5993 pharmacokinetic values.

\subsection{Safety and Tolerability}

The number and percentage of subjects reporting TEAEs are shown in Table 5. The number of events occurring during exposure to cimetidine + CHF 5993 was more than

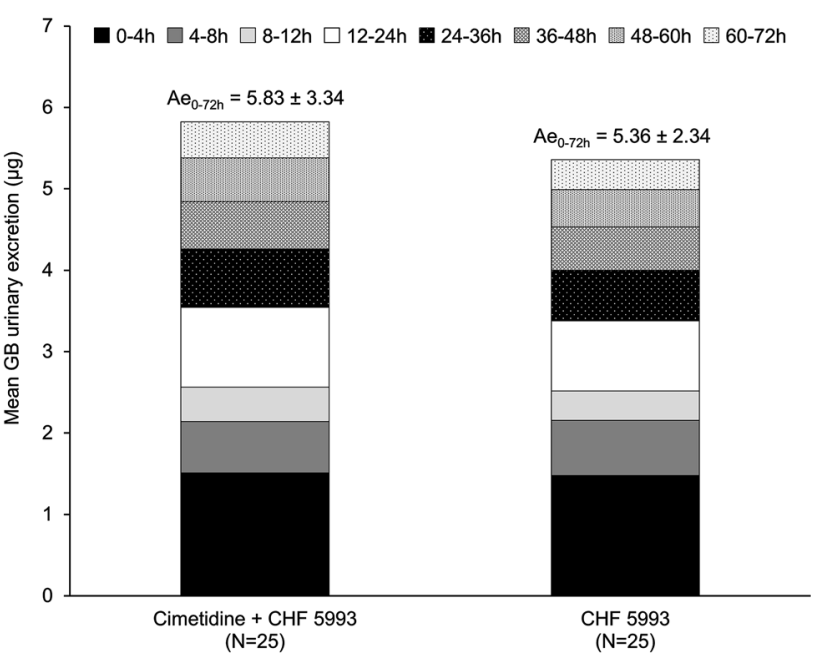

Fig. 3 Mean GB urinary excretion (pharmacokinetic population). Ae mean \pm standard deviation amount excreted, $G B$ glycopyrronium bromide

double the number of events occurring during CHF 5993 alone. However, the number of subjects experiencing at least one TEAE was comparable between the two periods. Moreover, no serious TEAEs were reported.

In terms of relationship to dosing of the TEAEs occurring in at least two subjects, 5 of the events with cimetidine + CHF 5993 started on the day that CHF 5993 was administered (abdominal pain, dizziness and three 


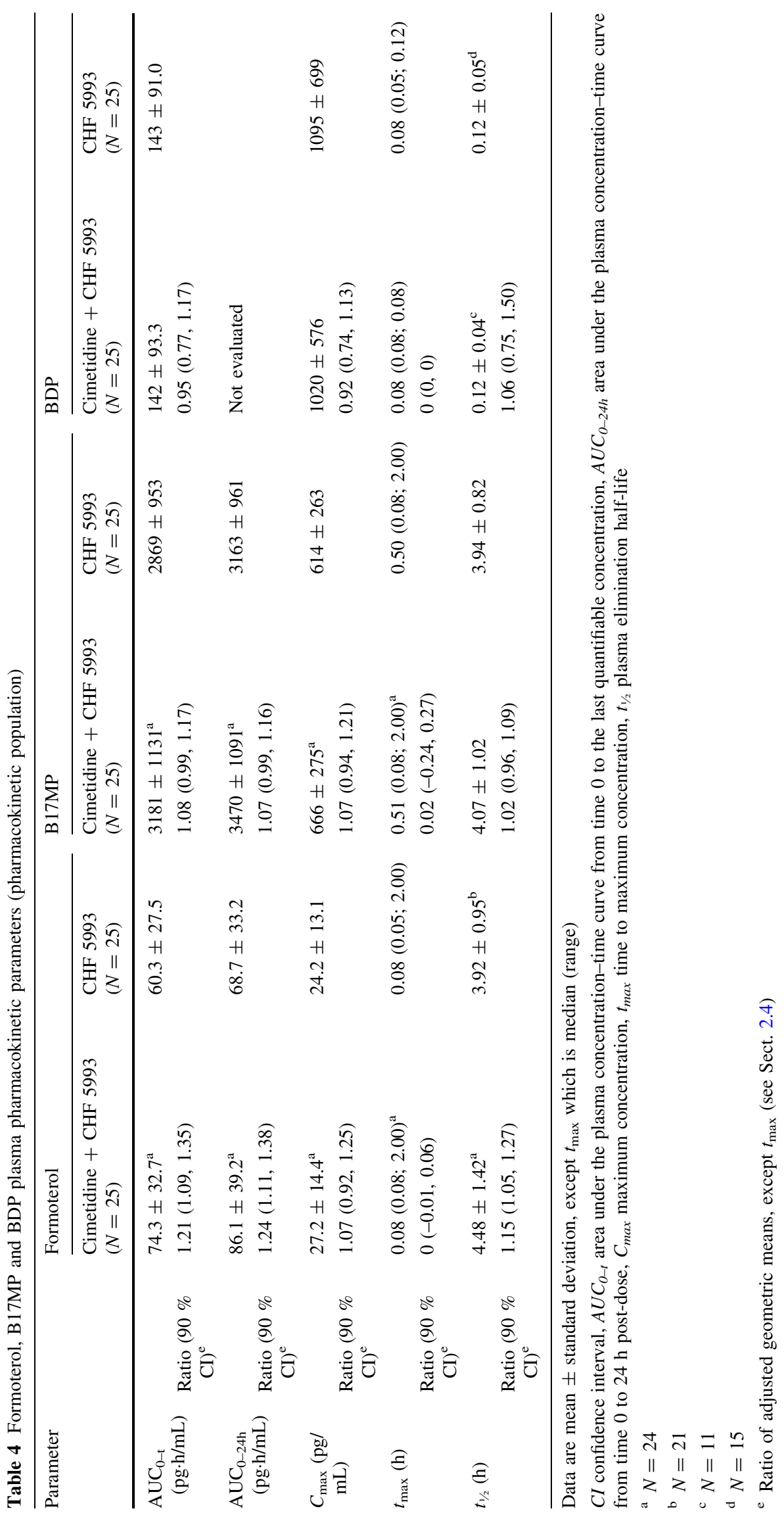




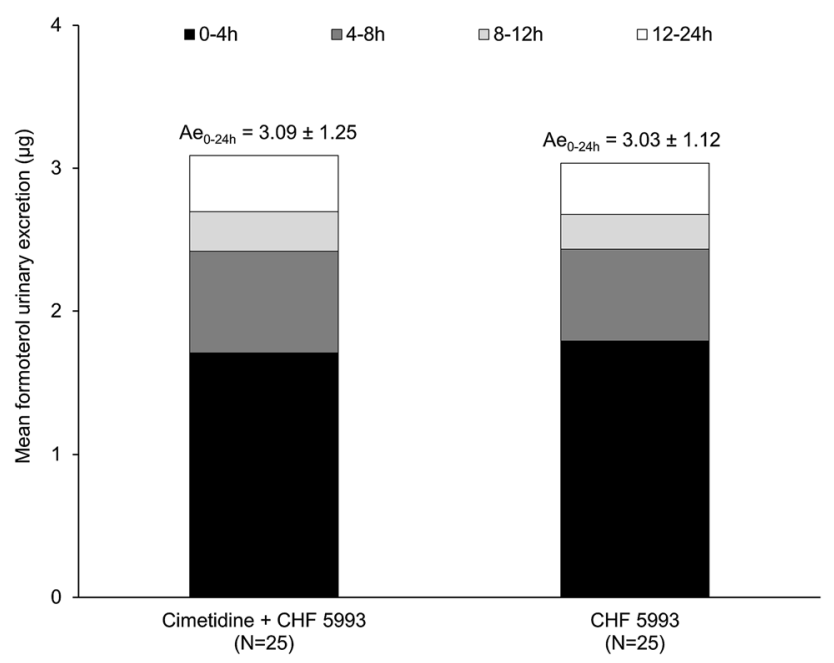

Fig. 4 Mean formoterol urinary excretion (pharmacokinetic population). Ae mean \pm standard deviation amount excreted

occurrences of headache), compared with 6 of the events with CHF 5993 alone (two each of abdominal discomfort, headache and vomiting). The other TEAEs in Table 5 were started on days when CHF 5993 was not administered.

\section{Discussion}

This study evaluated the extent of the drug-drug interaction between CHF 5993 and the OCT2/MATE1 inhibitor cimetidine. The component of CHF 5993 of particular interest in terms of this potential interaction is GB, since due to its pharmacokinetic profile, it is more susceptible to interaction with inhibitors of OCT1, OCT2 and MATE1 that are involved in GB renal and hepatic elimination. There were small, although statistically significant, increases in a number of the GB plasma pharmacokinetic parameters as a result of cimetidine co-administration, with total exposure increased by $16 \%$, and peak concentration by $26 \%$. GB was rapidly absorbed, reaching peak plasma concentration within $5 \mathrm{~min}$ (with or without cimetidine coadministration). GB was then rapidly eliminated, with the mean concentration below the LLOQ by $8 \mathrm{~h}$ post-dose. Urinary excretion was similarly rapid, with nearly $50 \%$ occurring in the first $12 \mathrm{~h}$. The CLr of unbound GB was 491 and $547 \mathrm{~mL} / \mathrm{min}$ for cimetidine + CHF 5993 and CHF 5993 alone, respectively; given the mean glomerular filtration rate was $95.3 \mathrm{~mL} / \mathrm{min} / 1.73 \mathrm{~m}^{2}$, this suggests that active transport was involved in the excretion of GB. Since drug-related safety would be anticipated to correlate with systemic exposure, the rapid excretion of GB and the relatively small increases in pharmacokinetic parameters resulting from cimetidine co-administration are reassuring-especially since the GB dose used in this study (a single dose of $100 \mu \mathrm{g}$ ) is four times the dose that in another study was minimally effective in patients with COPD (25 $\mu$ g BID) [21], and with no safety signal observed with single doses as high as $200 \mu \mathrm{g}$ [22]. These findings are further supported by the results from a previous 14-day study in which BDP/FF was administered in one inhaler and GB in a second to patients with COPD, the main aim of which was an investigation of cardiac safety (data on file). In this earlier study, GB 25 and $50 \mu \mathrm{g}$ BID added to BDP/ FF overall was not associated with an increased risk of an elevated heart rate (measured by means of 24-h digital Holter ECG) compared with BDP/FF alone, suggesting that an increase in GB exposure of $16 \%$ is unlikely to result in cardiovascular safety concerns.

These results are broadly consistent with a pharmacokinetic analysis of a standard particle formulation of glycopyrronium that has been approved for once-daily dosing (at a dose of $50 \mu \mathrm{g}$ daily), in which glycopyrronium plasma concentration also reached a peak rapidly (by 5 min

Table 5 Overall and most frequent (in $\geq 2$ subjects) treatment-emergent adverse events (safety population)

\begin{tabular}{|c|c|c|c|c|c|c|}
\hline \multirow[t]{2}{*}{ Parameter } & \multicolumn{2}{|c|}{ Cimetidine + CHF $5993(N=25)$} & \multicolumn{2}{|c|}{ CHF $5993(N=25)$} & \multicolumn{2}{|c|}{ All treatments $(N=25)$} \\
\hline & $n(\%)$ & Events & $n(\%)$ & Events & $n(\%)$ & Events \\
\hline At least one TEAE & $8(32.0)$ & 20 & $7(28.0)$ & 9 & $12(48.0)$ & 29 \\
\hline Treatment-related AE & $2(8.0)$ & 2 & $1(4.0)$ & 1 & $3(12.0)$ & 3 \\
\hline \multicolumn{7}{|c|}{ Most frequently reported TEAEs (in $\geq 2$ subjects during any treatment) } \\
\hline Headache & $4(16.0)$ & 4 & $3(12.0)$ & 3 & $6(24.0)$ & 7 \\
\hline Dizziness & $4(16.0)$ & 4 & 0 & 0 & $4(16.0)$ & 4 \\
\hline Abdominal pain & $3(12.0)$ & 3 & 0 & 0 & $3(12.0)$ & 3 \\
\hline Abdominal discomfort & 0 & 0 & $2(8.0)$ & 2 & $2(8.0)$ & 2 \\
\hline Vomiting & 0 & 0 & $2(8.0)$ & 2 & $2(8.0)$ & 2 \\
\hline
\end{tabular}

$N$ number of subjects in the safety population, $n$ number of subjects with event, TEAE treatment-emergent adverse event 
post-dose), and then rapidly declined [23]. Although it is difficult to compare these two studies directly, mean systemic exposure $\left(\mathrm{AUC}_{0-\mathrm{t}}\right)$ was lower for the extrafine particle formulation tested in the current study (330 and $272 \mathrm{pg} \cdot \mathrm{h} / \mathrm{mL}$ with and without cimetidine, respectively) than for the standard particle formulation (919 and $771 \mathrm{pg} \cdot \mathrm{h} / \mathrm{mL}$, respectively).

A high degree of variability of GB $C_{\max }$ was observed in this study, with standard deviations similar in size to the mean. Given most of the cimetidine doses (and all of the CHF 5993 doses) were administered at the clinic, this cannot be explained by compliance issues, and since all patients were trained on device use (with all inhalations observed), this is unlikely to be inhaler technique. The most logical explanation for this variability is the rapid metabolism and plasma elimination of GB. As can be seen from Fig. 3 and Table 3, the observed mean maximum plasma concentration was at the first sampling timepoint, with the concentration then rapidly decreasing. This plasma concentration-time profile makes it very difficult to capture the actual maximum plasma concentration for an individual patient. In contrast, the variability of the AUC parameters is much smaller, since these parameters are largely driven by samples taken at timepoints when the curve is flatter (and, therefore, individual patient variability has less impact on the results). This means that the two AUC parameters are more informative than $C_{\max }$ in terms of the effect of cimetidine on the pharmacokinetics of GB.

The apparent IC50 values for cimetidine inhibition of OCT2 and MATE1 are 23 and $5.7 \mu \mathrm{M}$, respectively [17]. Since the steady-state $C_{\max }$ of cimetidine after $800 \mathrm{mg}$ BID is estimated to be approximately $19 \mu \mathrm{M}$ (extrapolated from data reported for cimetidine $400 \mathrm{mg}$ BID [24]), the cimetidine dose used in the current study ( $800 \mathrm{mg}$ BID) is anticipated to result in plasma levels able to provide significant interaction with OCT2 and MATE1. Although there is some uncertainty over the extent of transporter inhibition that this cimetidine dose would induce, previous in vivo studies have demonstrated transporter inhibition at doses of 400 or $800 \mathrm{mg}$ BID [25, 26]. Some in vitro studies suggest that cimetidine is only a weak inhibitor of CYP2D6 [27] and CYP2C9 [28, 29]. However, other in vivo studies have shown that cimetidine decreased the systemic and metabolic clearance of tolbutamide (dependent on CYP2C9 activity) by approximately $40 \%$ at a dose of $1.6 \mathrm{~g} /$ day [30], of desipramine (dependent on CYP2D6 activity) by approximately $47 \%$ at a dose of $1.2 \mathrm{~g} /$ day [31], and of propranolol (CYP2D6 substrate) after a dose of $1 \mathrm{~g} /$ day [32]. Furthermore, in our study we observed statistically significant increases in formoterol systemic exposure that were consistent with the effects of cimetidine on cytochrome P450. Taken together, this evidence suggests that the cimetidine dose administered in our study was sufficient in terms of effect on metabolism and transporters.

As would be anticipated from the metabolism and excretion profiles, the plasma pharmacokinetic profiles for BDP and B17MP were not significantly impacted by coadministration of cimetidine. There were small but significant increases in formoterol systemic exposure (although not maximum concentration), consistent with the effect of cimetidine on cytochrome P450. However, in a 12-week study of a standard particle formulation of FF that compared FF $12 \mu \mathrm{g}$ BID with FF $24 \mu \mathrm{g}$ BID, ipratropium $40 \mu \mathrm{g}$ four times a day and placebo, the $24 \mu \mathrm{g}$ BID dose of FF was associated with a similar rate of AEs [33]. Whilst care should be taken comparing one formulation with another, this previous 12-week study does suggest that the $21 \%$ increase in systemic exposure observed in the current study is unlikely to result in safety concerns.

Although the current study cannot provide definitive data on the safety of CHF 5993, it is reassuring that few subjects experienced a treatment-related TEAE, and by comparing the treatments it would appear that cimetidine was responsible for most of the events-especially since headache and dizziness are common adverse reactions reported with cimetidine [18]. It is also notable that in longer term studies in patients with COPD, inhaled GB (in a different formulation) has demonstrated an overall favourable safety profile [34-36].

\section{Conclusions}

Overall, this study indicates that there is no clinically relevant drug-drug interaction between GB and the other components of the triple combination of $\mathrm{GB} / \mathrm{FF} / \mathrm{BDP}$ that comprise extrafine CHF 5993, and cimetidine, a potent inhibitor of organic cation transport. This reduces the likelihood of relevant interactions with other medications involved in the OCT2 and MATE1 pathways and potentially co-administered with CHF 5993. The study findings also support a favourable overall safety and tolerability profile for CHF 5993 when delivered in this setting.

Acknowledgments The authors would like to thank the investigators and subjects at the investigative site for their support of this study.

\section{Compliance with Ethical Standards}

This study was funded by Chiesi Farmaceutici SpA. Writing support was provided by David Young of Young Medical Communications and Consulting Ltd. This support was funded by Chiesi Farmaceutici SpA.

All procedures performed in studies involving human participants were in accordance with the ethical standards of the institutional and/ or national research committee and with the 1964 Helsinki declaration and its later amendments. Informed consent was obtained from all 
individual participants included in the study. FM is an employee of Chiesi Farmaceutici SpA. GC is an employee of Chiesi Farmaceutici SpA. LS is an employee of Chiesi Farmaceutici SpA. AM is an employee of Chiesi Farmaceutici SpA. DA is an employee of Chiesi Farmaceutici SpA.

Open Access This article is distributed under the terms of the Creative Commons Attribution-NonCommercial 4.0 International License (http://creativecommons.org/licenses/by-nc/4.0/), which permits any noncommercial use, distribution, and reproduction in any medium, provided you give appropriate credit to the original author(s) and the source, provide a link to the Creative Commons license, and indicate if changes were made.

\section{References}

1. Price D, West D, Brusselle G, Gruffydd-Jones K, Jones R, Miravitlles M, et al. Management of COPD in the UK primarycare setting: an analysis of real-life prescribing patterns. Int $\mathbf{J}$ Chron Obstruct Pulmon Dis. 2014;9:889-905.

2. Singh D, Brooks J, Hagan G, Cahn A, O'Connor BJ. Superiority of "triple" therapy with salmeterol/fluticasone propionate and tiotropium bromide versus individual components in moderate to severe COPD. Thorax. 2008;63:592-8.

3. Chatterjee A, Shah M, D'Souza AO, Bechtel B, Crater G, Dalal AA. Observational study on the impact of initiating tiotropium alone versus tiotropium with fluticasone propionate/salmeterol combination therapy on outcomes and costs in chronic obstructive pulmonary disease. Respir Res. 2012;13:15.

4. Jung KS, Park HY, Park SY, Kim SK, Kim Y-K, Shim J-J, et al. Comparison of tiotropium plus fluticasone propionate/salmeterol with tiotropium in COPD: a randomized controlled study. Respir Med. 2012;106:382-9.

5. Welte T, Miravitlles M, Hernandez P, Eriksson G, Peterson S, Polanowski T, et al. Efficacy and tolerability of budesonide/formoterol added to tiotropium in patients with chronic obstructive pulmonary disease. Am J Respir Crit Care Med. 2009;180:741-50.

6. Short PM, Williamson PA, Elder DHJ, Lipworth SIW, Schembri $\mathrm{S}$, Lipworth BJ. The impact of tiotropium on mortality and exacerbations when added to inhaled corticosteroids and longacting $\beta$-agonist therapy in COPD. Chest. 2012;141:81-6.

7. Scichilone N, Benfante A, Morandi L, Bellini F, Papi A. Impact of extrafine formulations of inhaled combinations on patient-related outcomes in asthma and COPD. Patient Relat Outcome Meas. 2014;5:153-62.

8. Mariotti F, Collarini S, Cuomo D, Muraro A, Acerbi D. Pharmacokinetics of a novel triple fixed dose combination metered dose inhaler: comparison with the free combination and the single components. Am J Respir Crit Care Med. 2016;193:A6830.

9. Martin LE, Tanner RJ, Clark TJ, Cochrane GM. Absorption and metabolism of orally administered beclomethasone dipropionate. Clin Pharmacol Ther. 1974; 15:267-75.

10. Daley-Yates PT, Price A, Pereira A. Systemic bioavailability of beclometasone dipropionate (BDP) following inhaled, intranasal, oral and intravenous dosing in man. Eur Respir J. 2000;16:280s.

11. Lecaillon JB, Kaiser G, Palmisano M, Morgan J, Della Cioppa G. Pharmacokinetics and tolerability of formoterol in healthy volunteers after a single high dose of Foradil dry powder inhalation via Aerolizer. Eur J Clin Pharmacol. 1999;55:131-8.

12. Rosenborg J, Larsson P, Tegnér K, Hallström G. Mass balance and metabolism of $[(3) \mathrm{H}]$ Formoterol in healthy men after combined i.v. and oral administration-mimicking inhalation. Drug Metab Dispos. 1999;27:1104-16.

13. Bindschedler M, Kaiser G, Preiswerk G, Patalano F. Biochemical and cardiovascular effects and urinary excretion of formoterol after single inhaled doses. Ann Allergy Asthma Immunol. 1998;80:P118.

14. Levien TL, Baker DE. Cytochrome P450 drug interactions. CA: Stockton; 2003.

15. Giacomini KM, Huang S-M, Tweedie DJ, Benet LZ, Brouwer KLR, Chu X, et al. Membrane transporters in drug development. Nat Rev Drug Discov. 2010;9:215-36.

16. Wittwer MB, Zur AA, Khuri N, Kido Y, Kosaka A, Zhang X, et al. Discovery of potent, selective multidrug and toxin extrusion transporter 1 (MATE1, SLC47A1) inhibitors through prescription drug profiling and computational modeling. J Med Chem. 2013;56:781-95.

17. Kido Y, Matsson P, Giacomini KM. Profiling of a prescription drug library for potential renal drug-drug interactions mediated by the organic cation transporter 2. J Med Chem. 2011;54:4548-58.

18. Chemidex Pharma Ltd. Tagamet $400 \mathrm{mg}$ Tablets summary of product characteristics; 2009.

19. European Medicines Agency. Guideline on bioanalytical method validation (EMEA/CHMP/EWP/192217/2009); 2011.

20. US Department of Health and Human Services Food and Drug Administration. Guidance for Industry-Bioanalytical Method Validation; 2001.

21. Singh D, Cuomo D, Collarini S, Vezzoli S, Mariotti F, Muraro A, et al. Sustained efficacy of multiple doses of extrafine glycopyrronium bromide in COPD patients. Am J Respir Crit Care Med. 2015;191:A5759 (American Thoracic Society).

22. Singh D, Cuomo D, Collarini S, Vezzoli S, Mariotti F, Acerbi D. A single dose escalation safety study of extrafine glycopyrronium bromide pMDI in COPD patients. Am J Respir Crit Care Med. 2015;191:A5761 (American Thoracic Society).

23. Dumitras S, Sechaud R, Drollmann A, Pal P, Vaidyanathan S, Camenisch $\mathrm{G}$, et al. Effect of cimetidine, a model drug for inhibition of the organic cation transport (OCT2/MATE1) in the kidney, on the pharmacokinetics of glycopyrronium. Int J Clin Pharmacol Ther. 2013;51:771-9.

24. Somogyi A, Stockley C, Keal J, Rolan P, Bochner F. Reduction of metformin renal tubular secretion by cimetidine in man. $\mathrm{Br} \mathrm{J}$ Clin Pharmacol. 1987;23:545-51.

25. Sitsen JM, Maris FA, Timmer CJ. Concomitant use of mirtazapine and cimetidine: a drug-drug interaction study in healthy male subjects. Eur J Clin Pharmacol. 2000;56:389-94.

26. Malling D, Poulsen MN, Søgaard B. The effect of cimetidine or omeprazole on the pharmacokinetics of escitalopram in healthy subjects. Br J Clin Pharmacol. 2005;60:287-90.

27. Martinez C, Albet C, Agundez JA, Herrero E, Carrillo JA, Marquez M, et al. Comparative in vitro and in vivo inhibition of cytochrome P450 CYP1A2, CYP2D6, and CYP3A by H2-receptor antagonists. Clin Pharmacol Ther. 1999;65:369-76.

28. Miners JO, Smith KJ, Robson RA, McManus ME, Veronese ME, Birkett DJ. Tolbutamide hydroxylation by human liver microsomes. Kinetic characterisation and relationship to other cytochrome P-450 dependent xenobiotic oxidations. Biochem Pharmacol. 1988;37:1137-44.

29. Back DJ, Tjia JF, Karbwang J, Colbert J. In vitro inhibition studies of tolbutamide hydroxylase activity of human liver microsomes by azoles, sulphonamides and quinolines. Br J Clin Pharmacol. 1988;26:23-9.

30. Back DJ, Tjia J, Mönig H, Ohnhaus EE, Park BK. Selective inhibition of drug oxidation after simultaneous administration of two probe drugs, antipyrine and tolbutamide. Eur J Clin Pharmacol. 1988;34:157-63. 
31. Steiner E, Spina E. Differences in the inhibitory effect of cimetidine on desipramine metabolism between rapid and slow debrisoquine hydroxylators. Clin Pharmacol Ther. 1987;42:278-82.

32. Reimann I, Klotz U, Siems B, Frolich J. Cimetidine increases steady state plasma levels of propranolol. Br J Clin Pharmacol. 1981;12:785-90.

33. Dahl R, Greefhorst LA, Nowak D, Nonikov V, Byrne AM, Thomson $\mathrm{MH}$, et al. Inhaled formoterol dry powder versus ipratropium bromide in chronic obstructive pulmonary disease. Am J Respir Crit Care Med. 2001;164:778-84.

34. Kerwin E, Hébert J, Gallagher N, Martin C, Overend T, Alagappan VKT, et al. Efficacy and safety of NVA237 versus placebo and tiotropium in patients with COPD: the GLOW2 study. Eur Respir J. 2012;40:1106-14.

35. D'Urzo A, Ferguson GT, van Noord JA, Hirata K, Martin C, Horton R, et al. Efficacy and safety of once-daily NVA237 in patients with moderate-to-severe COPD: the GLOW1 trial. Respir Res. 2011;12:156.

36. Wang C, Sun T, Huang Y, Humphries M, Bai L, Li L, et al. Efficacy and safety of once-daily glycopyrronium in predominantly Chinese patients with moderate-to-severe chronic obstructive pulmonary disease: the GLOW7 study. Int J Chron Obstruct Pulmon Dis. 2015;10:57-68. 